ORIGINAL ARTICLE

\section{Colonoscopy versus Fecal Immunochemical Testing in Colorectal-Cancer Screening}

\author{
Enrique Quintero, M.D., Ph.D., Antoni Castells, M.D., Ph.D., \\ Luis Bujanda, M.D., Ph.D., Joaquín Cubiella, M.D., Ph.D., Dolores Salas, M.D., \\ Ángel Lanas, M.D., Ph.D., Montserrat Andreu, M.D., Ph.D., \\ Fernando Carballo, M.D., Ph.D., Juan Diego Morillas, M.D., Ph.D., \\ Cristina Hernández, B.Sc., Rodrigo Jover, M.D., Ph.D., Isabel Montalvo, M.D., Ph.D., \\ Juan Arenas, M.D., Ph.D., Eva Laredo, R.N., Vicent Hernández, M.D., Ph.D., \\ Felipe Iglesias, R.N., Estela Cid, R.N., Raquel Zubizarreta, M.D., Teresa Sala, M.D., \\ Marta Ponce, M.D., Mercedes Andrés, M.D., Gloria Teruel, M.D., Antonio Peris, M.D., \\ María-Pilar Roncales, R.N., Mónica Polo-Tomás, M.D., Ph.D., \\ Xavier Bessa, M.D., Ph.D., Olga Ferrer-Armengou, R.N., Jaume Grau, M.D., \\ Anna Serradesanferm, R.N., Akiko Ono, M.D., José Cruzado, M.D., \\ Francisco Pérez-Riquelme, M.D., Inmaculada Alonso-Abreu, M.D., \\ Mariola de la Vega-Prieto, M.D., Juana Maria Reyes-Melian, M.D., \\ Guillermo Cacho, M.D., José Díaz-Tasende, M.D., Alberto Herreros-de-Tejada, M.D., \\ Carmen Poves, M.D., Cecilio Santander, M.D., and Andrés González-Navarro, M.D., \\ for the COLONPREV Study Investigators*
}

\section{A B S T R ACT}

\section{BACKGROUND}

Colonoscopy and fecal immunochemical testing (FIT) are accepted strategies for colorectal-cancer screening in the average-risk population.

\section{METHODS}

In this randomized, controlled trial involving asymptomatic adults 50 to 69 years of age, we compared one-time colonoscopy in 26,703 subjects with FIT every 2 years in 26,599 subjects. The primary outcome was the rate of death from colorectal cancer at 10 years. This interim report describes rates of participation, diagnostic findings, and occurrence of major complications at completion of the baseline screening. Study outcomes were analyzed in both intention-to-screen and as-screened populations.

\section{RESULTS}

The rate of participation was higher in the FIT group than in the colonoscopy group (34.2\% vs. $24.6 \%, \mathrm{P}<0.001)$. Colorectal cancer was found in 30 subjects $(0.1 \%)$ in the colonoscopy group and 33 subjects $(0.1 \%)$ in the FIT group (odds ratio, $0.99 ; 95 \%$ confidence interval [CI], 0.61 to $1.64 ; \mathrm{P}=0.99)$. Advanced adenomas were detected in 514 subjects $(1.9 \%)$ in the colonoscopy group and 231 subjects $(0.9 \%)$ in the FIT group (odds ratio, 2.30; 95\% CI, 1.97 to 2.69; $\mathrm{P}<0.001$ ), and nonadvanced adenomas were detected in 1109 subjects (4.2\%) in the colonoscopy group and 119 subjects $(0.4 \%)$ in the FIT group (odds ratio, $9.80 ; 95 \% \mathrm{CI}, 8.10$ to 11.85 ; $\mathrm{P}<0.001$ ).

\section{CONCLUSIONS}

Subjects in the FIT group were more likely to participate in screening than were those in the colonoscopy group. On the baseline screening examination, the numbers of subjects in whom colorectal cancer was detected were similar in the two study groups, but more adenomas were identified in the colonoscopy group. (Funded by Instituto de Salud Carlos III and others; ClinicalTrials.gov number, NCT00906997.)
The authors' affiliations are listed in the Appendix. Address reprint requests to Dr. Castells at the Department of Gastroenterology, Hospital Clínic, Villarroel 170, 08036 Barcelona, Spain, or at castells@ clinic.ub.es; or to Dr. Quintero at the Department of Gastroenterology, Hospital Universitario de Canarias, Ctra. Ofra S/N Cuesta, 38320 La Laguna, Tenerife, Spain, or at equinter@gmail.com.

Drs. Quintero and Castells contributed equally to this article.

*The investigators in the COLONPREV study are listed in the Supplementary Appendix, available at NEJM.org.

N Engl J Med 2012;366:697-706. Copyright (c) 2012 Massachusetts Medical Society. 
OLORECTAL CANCER IS THE THIRD MOST common cancer worldwide and the second leading cause of cancer-related deaths. ${ }^{1}$ Several studies have shown that colorectal-cancer screening is effective $e^{2-5}$ and cost-effective ${ }^{6}$ in the average-risk population.

Recommended strategies for colorectal-cancer screening fall into two broad categories: stool tests (occult blood and exfoliated DNA tests) and structural examinations (flexible sigmoidoscopy, colonoscopy, and computed tomographic colonography). Stool tests primarily detect cancer, and structural examinations detect both cancer and premalignant lesions. ${ }^{2}$ Stool tests for occult blood (guaiac testing and fecal immunochemical testing [FIT]) are predominantly used in Europe and Australia, whereas colonoscopy is the predominant screening method in the United States.

Colonoscopy is considered the most accurate test for early detection and prevention of colorectal cancer. Although data from randomized studies evaluating the effect of colonoscopy on the rate of death from colorectal cancer are lacking, the procedure is recommended as a first-line screening test on the basis of indirect data and observational studies. Population-based case-control studies have suggested that colonoscopy markedly reduces the risk of colorectal cancer ${ }^{7,8}$ and death. ${ }^{9}$ Recent evidence suggests that patients with no abnormalities on a previous colonoscopy have a markedly reduced risk of colorectal cancer. ${ }^{8,10,11}$ In a cohort of average-risk subjects, the use of screening colonoscopy was associated with a reduction in the incidence of colorectal cancer of $67 \%$ and a reduction in the rate of death of $65 \% .{ }^{12}$ Cohort studies involving patients with adenomas have suggested that polypectomy can prevent approximately $80 \%$ of colorectal cancers. ${ }^{13,14}$

Comparative studies have shown that the semiquantitative FIT is more accurate than the guaiac test for the detection of colorectal cancer and advanced adenomas, ${ }^{15-19}$ and this new test is now recommended as the first-choice fecal occult blood test in colorectal-cancer screening. Although FIT is less effective for neoplastic detection than colonoscopy or sigmoidoscopy, evidence suggests that it may be better accepted, ${ }^{20,21}$ and higher acceptance may counteract its lower detection capacity. It has been suggested that FIT may be more effective and less costly than other screening strategies. We conducted a randomized, controlled trial to compare semiquantitative FIT with colonos- copy. We hypothesized that FIT screening every 2 years would be noninferior to one-time colonoscopy with respect to a reduction in mortality related to colorectal cancer among average-risk subjects. This interim report describes rates of participation, diagnostic findings, and the occurrence of major complications at the completion of the baseline screening.

\section{METHODS}

\section{STUDY DESIGN}

We conducted this randomized, controlled, noninferiority trial in eight Spanish regions (Aragón, Basque Country, Canarias, Catalonia, Galicia, Madrid, Murcia, and Valencia) with the participation of 15 tertiary care hospitals. The study was designed to assess the efficacy of one-time colonoscopy and biennial FIT for reducing the rate of death from colorectal cancer at 10 years (primary trial outcome). The study started in November 2008 with an informative nationwide campaign. ${ }^{22}$ The recruitment period was initiated in June 2009, and the first round finished in June 2011. Ten-year follow-up will be completed in 2021 .

The study protocol (available with the full text of this article at NEJM.org) was approved by the ethics committee at each hospital, and all subjects provided written informed consent.

\section{STUDY POPULATION}

Asymptomatic men and women between the ages of 50 and 69 years were eligible for enrollment. Exclusion criteria, which were ascertained after randomization by means of a questionnaire at the local screening office, included a personal history of colorectal cancer, adenoma, or inflammatory bowel disease; a family history of hereditary or familial colorectal cancer (i.e., $\geq 2$ first-degree relatives with colorectal cancer or 1 in whom the disease was diagnosed before the age of 60 years) ${ }^{23,24}$; a severe coexisting illness; and previous colectomy. Subjects were also temporarily excluded if they had undergone fecal occult blood testing in the previous 2 years or sigmoidoscopy or colonoscopy within the previous 5 years or if they had symptoms requiring additional workup. The subjects with previous screening tests became eligible when sufficient time had elapsed since the tests, ${ }^{2}$ and those with symptoms became eligible if the results of the clinical workup were negative. 


\section{RANDOMIZATION}

Subjects were identified through each Community Health Registry, sorted according to household, and stratified according to age (in 5-year age groups) and sex. Households were randomly assigned in a 1:1 ratio to undergo either one-time colonoscopy or biennial FIT. Randomization was performed before invitation with the use of a computer-generated allocation algorithm on the basis of a randomizedblocks method. Subjects were sent a preinvitation letter containing information on colorectal-cancer screening and the rationale for the study. Two weeks later, an invitation letter was sent indicating the subject's study-group assignment. Two additional, reminder letters were mailed 3 and 6 months after the invitation to subjects who did not respond to the first mailed invitation. Subjects who agreed to participate in the study received an appointment at the local screening office, where they completed the questionnaire. The study design allowed for crossover between the two study groups.

\section{STUDY INTERVENTIONS}

Among patients undergoing colonoscopy, bowel cleansing and sedation were performed as described previously. ${ }^{25}$ All colonoscopies were performed by experienced endoscopists (those who had performed $>200$ colonoscopies per year). ${ }^{26}$ Polyps were categorized as non-neoplastic or neoplastic. Adenomas measuring $10 \mathrm{~mm}$ or more in diameter, with villous architecture, high-grade dysplasia, or intramucosal carcinoma, were classified as advanced adenomas. Invasive cancer was considered to be present when malignant cells were observed beyond the muscularis mucosae. Advanced neoplasm was defined as advanced adenoma or invasive cancer. Tumor staging, performed according to the classification system of the American Joint Committee on Cancer, ${ }^{27}$ was based on the most advanced lesion.

The FIT strategy consisted of analysis of a single stool sample with the use of the automated semiquantitative OC-Sensor (Eiken Chemical) without specific restrictions on diet or medication use. Samples were processed as described previously ${ }^{28}$ at each regional hospital. Subjects who were found to have a hemoglobin level of $75 \mathrm{ng}$ per milliliter or more were invited to undergo colonoscopy.

Details regarding quality indicators for colonoscopy are provided in the study protocol and in Table 1 in the Supplementary Appendix, available at NEJM.org.

\section{STUDY OVERSIGHT}

Palex Medical and Biogen Diagnóstica donated supplies and automated fecal occult-blood analyzers used for FIT but provided no other support for the study. The companies were not involved in the design of the study, in the analysis or interpretation of the data, or in the preparation of the manuscript.

\section{STATISTICAL ANALYSIS}

This study was based on the assumption that screening average-risk subjects by means of biennial FIT would not be inferior to one-time colonoscopy with respect to the rate of death from colorectal cancer at 10 years. The calculations were based on an overall compliance rate of $30 \%$ and a crude 10-year rate of death from colorectal cancer of $6.96 \% .{ }^{29}$ Therefore, assuming a crude 10 -year rate of death from colorectal cancer of $1.74 \%$ among subjects undergoing colonoscopy (a 75\% reduction) and of $3.41 \%$ among those screened by means of FIT (a 51\% reduction) and accepting a noninferiority condition if the absolute difference was below 1.6 percentage points, we determined that a sample of 55,498 subjects (27,749 in each study group) would provide a power of $80 \%$. A P value of less than 0.025 was considered to indicate statistical significance with the use of a one-sided test of proportions. $^{30}$

We assessed study outcomes in both intentionto-screen and as-screened analyses. In the latter analysis, the detection rate was calculated as the number of subjects with true positive results divided by the number of subjects who actually underwent testing. The diagnostic yield was the number of subjects with true positive results divided by the number of eligible subjects in the intention-to-screen analysis. Subjects were excluded from the intention-to-screen analysis if they attended the screening office visit and met one or more exclusion criteria. Subjects who did not attend the screening office visit and thus did not provide information about exclusion criteria were classified as eligible and were included in the intention-to-screen analysis. Definitions of other outcomes are provided in the study protocol. Between-group differences in rates of participation, diagnostic yield, detection, and complications were established by logistic-regression analysis, with adjustment for age, sex, and participating center, and are reported as odds ratios with $95 \%$ confidence intervals. All analyses were performed with the use of SPSS statistical software, version 15.0. 


\section{RESULTS}

STUDY POPULATION

Overall, 57,404 subjects were randomly assigned to undergo either colonoscopy or FIT. Of these subjects, 1970 could not be contacted and 2132 were excluded either permanently $(1.7 \%$ in the colonoscopy group and $1.3 \%$ in the FIT group, $\mathrm{P}=0.20$ ) or temporarily $(2.2 \%$ in the colonoscopy group and $2.2 \%$ in the FIT group, $\mathrm{P}=0.11$ ) (Fig. 1). The eligible population consisted of 26,703 subjects in the colonoscopy group and 26,599 in the FIT group. The two groups were almost identical regarding both mean $( \pm S D)$ age $(59.2 \pm 5.5$ years in the colonoscopy group and $59.3 \pm 5.6$ years in the FIT group, $\mathrm{P}=0.35$ ) and the proportion of subjects who were women (53.5\% in the colonoscopy group and $54.3 \%$ in the FIT group, $\mathrm{P}=0.25$ ).

\section{PARTICIPATION}

Among subjects who were assigned to undergo colonoscopy, 5649 subjects accepted the proposed strategy, whereas 1706 requested to be screened by means of FIT (Fig. 1). Of the 5649 subjects who agreed to undergo colonoscopy, 4953 actually did so, and 1628 underwent FIT, for a participation rate of $24.6 \%$, according to the intention-to-screen analysis (average age, 59.1 \pm 5.5 years; proportion of subjects who were women, 53.4\%). Among subjects who were assigned to undergo FIT, 9353 subjects accepted the proposed strategy, whereas 117 asked to be screened by colonoscopy. A total of 8983 subjects underwent FIT, and 106 underwent colonoscopy, for an overall participation rate of $34.2 \%$ (average age, $59.3 \pm 5.6$ years; proportion of subjects who were women, $54.4 \%)$. Therefore, there were differences between study groups regarding both the rate of participation (odds ratio in the colonoscopy group, 0.63 ; $95 \%$ confidence interval [CI], 0.60 to $0.65 ; \mathrm{P}<0.001$ ) and the crossover rate (odds ratio, 16.8; 95\% CI, 13.9 to 20.2 ; $\mathrm{P}<0.001)$.

\section{DIAGNOSTIC YIELD}

In the intention-to-screen analysis, colorectal cancer was detected in 30 subjects $(0.1 \%)$ in the colonoscopy group and in 33 subjects $(0.1 \%)$ in the FIT group (odds ratio in the colonoscopy group, 0.99; 95\% CI, 0.61 to 1.64; $\mathrm{P}=0.99$ ) (Table 1 ). Advanced adenomas were found in 514 subjects (1.9\%) in the colonoscopy group and in 231 subjects $(0.9 \%)$ in the FIT group (odds ratio, 2.30; 95\% CI, 1.97 to
2.69; $\mathrm{P}<0.001)$. Nonadvanced adenomas were found in 1109 subjects (4.2\%) in the colonoscopy group and in 119 subjects $(0.4 \%)$ in the FIT group (odds ratio, 9.80; $95 \% \mathrm{CI}, 8.10$ to $11.85 ; \mathrm{P}<0.001)$.

When the diagnostic yield was analyzed according to the location of lesions, no significant between-group difference was found for either proximal or distal colorectal cancer (Table 2). However, colonoscopy performed significantly better than FIT in the diagnosis of advanced and nonadvanced adenomas that were either proximal or distal to the splenic flexure. The superior diagnostic yield of colonoscopy for advanced adenomas was most evident for lesions in the proximal colon (Table 2).

\section{DETECTION RATE}

On the basis of the screening that was actually performed, 5059 subjects underwent colonoscopy and 10,611 underwent FIT (Fig. 1). Among subjects who were screened by means of FIT, $767(7.2 \%)$ tested positive, and 663 of these subjects (86.4\%) underwent colonoscopy. Among subjects who were screened by means of colonoscopy, $27(0.5 \%)$ were found to have colorectal cancer, as compared with 36 subjects $(0.3 \%)$ who were screened by means of FIT (odds ratio, 1.56; 95\% CI, 0.93 to $2.56 ; \mathrm{P}=0.09$ ) (Table 3).

Tumor staging was similar in the two groups. In the FIT group, 24 tumors were stage I, 6 were stage II, and 6 were stage III. In the colonoscopy group, 19 tumors were stage I, 6 were stage II, and 2 were stage III $(\mathrm{P}=0.52)$. Colonoscopy was superior to FIT in the rates of detection of advanced adenomas (odds ratio, 4.32; 95\% CI, 3.69 to 5.07; $\mathrm{P}<0.001$ ) and nonadvanced adenomas (odds ratio, 25.98; 95\% CI, 21.27 to 31.74; $\mathrm{P}<0.001$ ) (Table 3).

No significant difference was observed in the rate of detection of colorectal cancer when subjects were stratified according to tumor location (Table 2 in the Supplementary Appendix). However, colonoscopy performed better than FIT with respect to detection rates for advanced and nonadvanced adenomas in both the proximal and distal colon.

\section{ANALYSIS OF RESOURCES}

The numbers of subjects who needed to be screened to find one colorectal cancer were 191 in the colonoscopy group and 281 in the FIT group, and the numbers who needed to be screened to find any advanced neoplasm were 10 and 36, respectively (Table 3 in the Supplementary Appendix). However, 


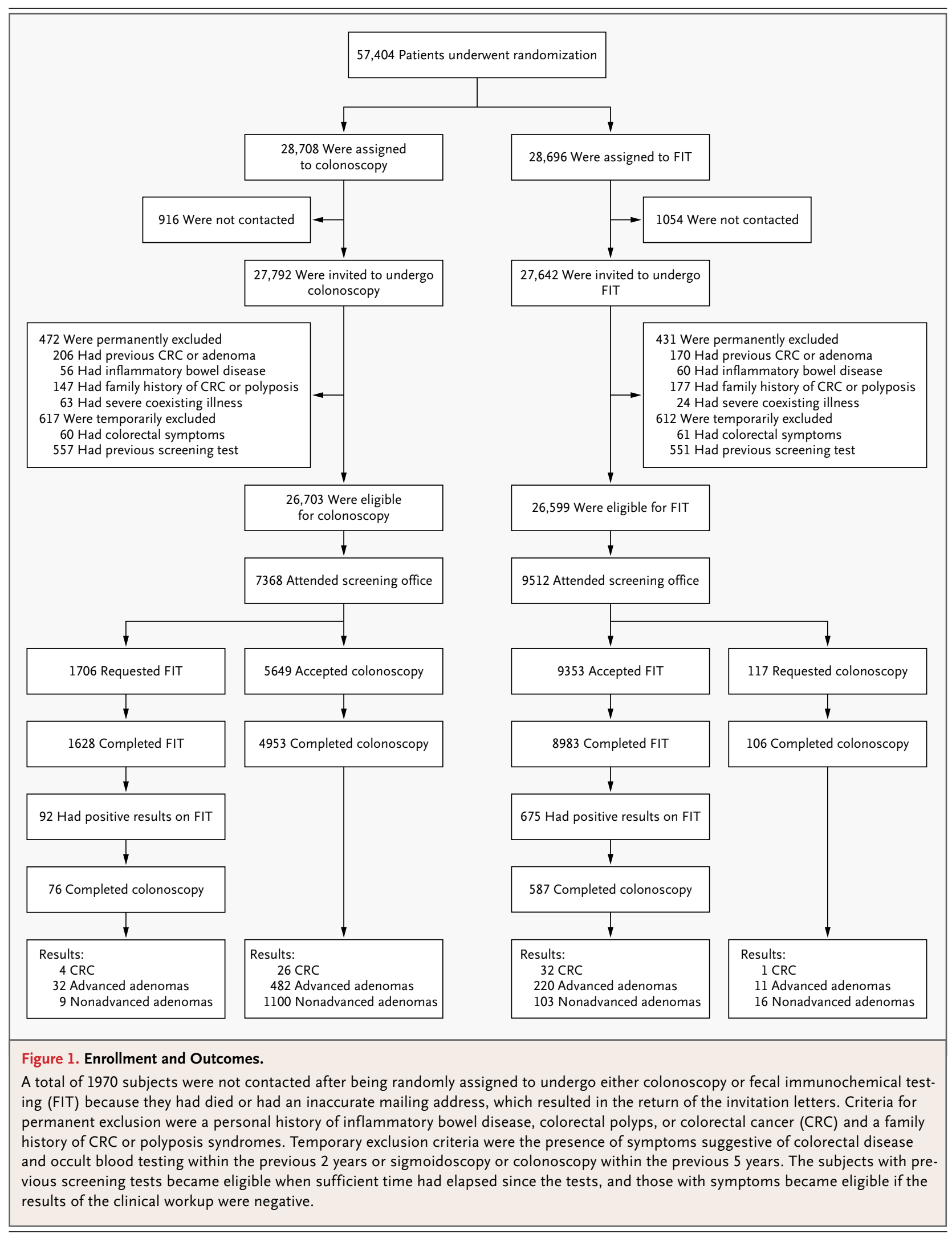




\begin{tabular}{|c|c|c|c|c|c|c|}
\hline \multirow[t]{2}{*}{ Colorectal Lesion } & \multicolumn{2}{|c|}{$\begin{array}{l}\text { Colonoscopy } \\
(\mathrm{N}=26,703)\end{array}$} & \multicolumn{2}{|c|}{$\begin{array}{c}\text { FIT } \\
(N=26,599)\end{array}$} & \multirow[t]{3}{*}{$\begin{array}{l}\text { Odds Ratio } \\
(95 \% \mathrm{Cl}) \dot{\dagger}\end{array}$} & \multirow[t]{3}{*}{ P Value } \\
\hline & Subjects & Rate & Subjects & Rate & & \\
\hline & no. & $\%$ & no. & $\%$ & & \\
\hline Cancer & 30 & 0.1 & 33 & 0.1 & $0.99(0.61-1.64)$ & 0.99 \\
\hline Advanced adenoma & 514 & 1.9 & 231 & 0.9 & 2.30 (1.97-2.69) & $<0.001$ \\
\hline Advanced neoplasia』 & 544 & 2.0 & 264 & 1.0 & 2.14 (1.85-2.49) & $<0.001$ \\
\hline Nonadvanced adenoma & 1109 & 4.2 & 119 & 0.4 & $9.80(8.10-11.85)$ & $<0.001$ \\
\hline Any neoplasia & 1653 & 6.2 & 383 & 1.4 & $4.67(4.17-5.24)$ & $<0.001$ \\
\hline
\end{tabular}

* The diagnostic yield was calculated as the number of subjects with true positive results divided by the number of subjects who were eligible to undergo testing. Subjects were classified according to the most advanced lesion.

$\dagger$ Odds ratios were adjusted for age, sex, and participating center. $\mathrm{Cl}$ denotes confidence interval.

$\lceil$ Advanced adenoma was defined as an adenoma measuring $10 \mathrm{~mm}$ or more in diameter, with villous architecture (>25\%), high-grade dysplasia, or intramucosal carcinoma.

$\int$ Advanced neoplasia was defined as advanced adenoma or cancer.

the numbers of subjects who needed to undergo colonoscopy to find one colorectal cancer were 191 in the colonoscopy group and 18 in the FIT group; to find any advanced neoplasm, the numbers were 10 and 2, respectively (Table 3 in the Supplementary Appendix).

\section{COMPLICATIONS}

Major complications occurred in 24 subjects $(0.5 \%)$ in the colonoscopy group (12 subjects with bleeding, 10 subjects with hypotension or bradycardia, 1 subject with perforation, and 1 subject with desaturation) and in 10 subjects (0.1\%) in the FIT group ( 8 subjects with bleeding and 2 subjects with hypotension or bradycardia, all of whom required colonoscopy because of a positive result on FIT). Accordingly, the complication rate was higher in the colonoscopy group than in the FIT group (odds ratio, 4.81; 95\% CI, 2.26 to $10.20 ; \mathrm{P}<0.001)$.

\section{DISCUSSION}

In this trial, participation rates were low in both groups of subjects who were invited to undergo colorectal-cancer screening, but subjects in the FIT group were more likely to agree to participate than those in the colonoscopy group. The number of patients in whom colorectal cancer was detected was similar in the two study groups, but more patients with adenomas were identified in the colonoscopy group. Since the primary outcome of this trial is the reduction in the rate of death from colorectal can- cer at 10 years, the relative benefits and risks of the two strategies will be assessed at the end of the trial.

Our study has a number of strengths. We used a randomized design to compare a sensitive, semiquantitative FIT with colonoscopy. The study design accepts crossover between groups and includes intention-to-screen and as-screened analyses. ${ }^{9}$ Our analyses incorporated stratification of results according to the location of detected lesions, thus allowing assessment of differences in procedure performance in both the proximal and distal colon, a critical issue that has become controversial in recent years. ${ }^{31}$

However, the study also has a number of limitations. First, the generalizability of the study findings is limited because participation in each screening strategy, a critical aspect with a direct effect on the diagnostic yield, depends on several factors and varies geographically. To overcome this limitation, we also evaluated the rate of detection of the screening procedure that was actually performed in order to establish the intrinsic efficacy of both strategies. Second, although recruitment was encouraged, the rate of participation was lower than expected according to European population-based screening programs ${ }^{5}$ and American colonoscopy-based strategies. ${ }^{31}$ However, it is important to note that our participation rate did not differ from the corresponding rates in other trials that were performed in a similar setting. ${ }^{19,21}$

The most relevant result of this interim analysis 


\begin{tabular}{|c|c|c|c|c|c|c|}
\hline \multirow[t]{2}{*}{ Colorectal Lesion } & \multicolumn{2}{|c|}{$\begin{array}{l}\text { Colonoscopy } \\
(N=26,703)\end{array}$} & \multicolumn{2}{|c|}{$\begin{array}{c}\text { FIT } \\
(\mathrm{N}=26,599)\end{array}$} & \multirow[t]{3}{*}{$\begin{array}{l}\text { Odds Ratio } \\
(95 \% \mathrm{Cl}) \grave{i}\end{array}$} & \multirow[t]{3}{*}{$P$ Value } \\
\hline & Subjects & Rate & Subjects & Rate & & \\
\hline & no. & $\%$ & no. & $\%$ & & \\
\hline \multicolumn{7}{|l|}{ Cancer } \\
\hline Proximal & 6 & $<0.1$ & 11 & $<0.1$ & $0.56(0.21-1.53)$ & 0.26 \\
\hline Distal & 25 & 0.1 & 23 & 0.1 & $1.22(0.69-2.16)$ & 0.49 \\
\hline \multicolumn{7}{|c|}{ Advanced adenomatr } \\
\hline Proximal & 199 & 0.7 & 51 & 0.2 & $4.06(2.98-5.53)$ & $<0.001$ \\
\hline Distal & 365 & 1.4 & 206 & 0.8 & $1.82(1.53-2.16)$ & $<0.001$ \\
\hline \multicolumn{7}{|c|}{ Advanced neoplasia』 } \\
\hline Proximal & 205 & 0.8 & 62 & 0.2 & $3.44(2.58-4.57)$ & $<0.001$ \\
\hline Distal & 390 & 1.5 & 229 & 0.9 & $1.76(1.49-2.08)$ & $<0.001$ \\
\hline \multicolumn{7}{|c|}{ Nonadvanced adenoma } \\
\hline Proximal & 608 & 2.3 & 62 & 0.2 & $10.06(7.74-13.08)$ & $<0.001$ \\
\hline Distal & 677 & 2.5 & 85 & 0.3 & 8.21 (6.55-10.29) & $<0.001$ \\
\hline \multicolumn{7}{|l|}{ Any neoplasia } \\
\hline Proximal & 813 & 3.0 & 124 & 0.5 & $6.84(5.65-8.27)$ & $<0.001$ \\
\hline Distal & 1067 & 4.0 & 314 & 1.2 & $3.58(3.15-4.07)$ & $<0.001$ \\
\hline
\end{tabular}

* The diagnostic yield was calculated as the number of subjects with true positive results divided by the number of subjects who were eligible to undergo testing. Subjects were classified according to the most advanced lesion that was proximal or distal to the splenic flexure. The total number of subjects with proximal and distal lesions may exceed the total number of subjects because subjects could have lesions in both locations.

$\uparrow$ Odds ratios were adjusted for age, sex, and participating center.

Advanced adenoma was defined as an adenoma measuring $10 \mathrm{~mm}$ or more in diameter, with villous architecture (>25\%), high-grade dysplasia, or intramucosal carcinoma.

$\int$ Advanced neoplasia was defined as either advanced adenoma or cancer.

is that one-time screening with FIT was very similar to one-time colonoscopy with respect to the rate of detection of colorectal cancer, and there was no significant difference in the stage of tumors detected by the two strategies. Additional cases of colorectal cancer might be detected during ongoing biennial FIT screening, and this could lead to an increased rate of cancer detection and a decreased rate of death in this group. On the other hand, more tumors might have been prevented in the colonoscopy group owing to the larger number of adenomas detected and removed, in comparison with the FIT group.

The higher detection rate and diagnostic yield of colonoscopy with respect to premalignant lesions also warrant comment. First, since advanced adenomas are usually considered a surrogate marker for colorectal cancer, ${ }^{32,33}$ the superiority of colonoscopy for detecting such lesions should be considered a potential advantage of this strategy in terms of reducing not only the rate of death from colorectal cancer but also the incidence of disease. ${ }^{34}$ However, this effect was diminished in our study by the lower participation rate in the colonoscopy group than in the FIT group. Moreover, the first round of FIT screening detected about half the number of advanced adenomas that were detected by colonoscopy. The lower participation rate in the colonoscopy group and the recurrent nature of FIT screening may reduce the apparent advantage of colonoscopy. On the other hand, the remarkably high detection rate with colonoscopy for patients with nonadvanced adenomas is more difficult to interpret. Most of these lesions correspond to low-risk adenomas, with a natural history that is more unpredictable but unquestionably less prone to progression to colorectal cancer than the natural history of advanced adenoma. ${ }^{34,35}$ Indeed, 


\begin{tabular}{|c|c|c|c|c|c|c|}
\hline \multirow[t]{2}{*}{ Colorectal Lesion } & \multicolumn{2}{|c|}{$\begin{array}{l}\text { Colonoscopy } \\
(\mathrm{N}=5059)\end{array}$} & \multicolumn{2}{|c|}{$\begin{array}{c}\text { FIT } \\
(\mathrm{N}=10,507) \dagger\end{array}$} & \multirow[t]{3}{*}{$\begin{array}{l}\text { Odds Ratio } \\
(95 \% \mathrm{Cl}) \div\end{array}$} & \multirow[t]{3}{*}{ P Value } \\
\hline & Subjects & Rate & Subjects & Rate & & \\
\hline & no. & $\%$ & no. & $\%$ & & \\
\hline Cancer & 27 & 0.5 & 36 & 0.3 & $1.56(0.93-2.56)$ & 0.09 \\
\hline Advanced adenoma $\mathbb{S}$ & 493 & 9.7 & 252 & 2.4 & $4.32(3.69-5.07)$ & $<0.001$ \\
\hline Advanced neoplasia & 520 & 10.3 & 288 & 2.7 & $4.01(3.45-4.67)$ & $<0.001$ \\
\hline Nonadvanced adenoma & 1116 & 22.1 & 112 & 1.1 & $25.98(21.27-31.74)$ & $<0.001$ \\
\hline Any neoplasia & 1636 & 32.3 & 400 & 3.8 & $12.28(10.89-13.84)$ & $<0.001$ \\
\hline
\end{tabular}

* The detection rate is the comparison between the number of positive results and the number of subjects who actually underwent testing. Subjects were classified according to the most advanced lesion.

$\uparrow$ A total of 104 subjects with positive results on FIT did not undergo colonoscopy.

Odds ratios were adjusted according to age, sex, and participating center.

$\int$ Advanced adenoma was defined as an adenoma measuring $10 \mathrm{~mm}$ or more in diameter, with villous architecture $(>25 \%)$, high-grade dysplasia, or intramucosal carcinoma.

1 Advanced neoplasia was defined as advanced adenoma or cancer.

recent European guidelines for quality assurance in colorectal-cancer screening consider patients with only one or two small adenomas $(<10 \mathrm{~mm}$ in diameter) to be at low risk and thus to be appropriate candidates for the same screening strategy that is recommended for patients without adenomas. ${ }^{36}$ Accordingly, the lower rate of detection of these lesions among patients who underwent screening by means of FIT might be seen as an additional advantage of this strategy, since it would reduce the number of patients who would need to undergo colonoscopy, with consequent reductions in costs and colonoscopy-related complications. This issue will be assessed at the end of the trial.

An interesting aspect of our study is the differential performance of screening strategies according to the location of the neoplasm. This aspect of colorectal-cancer screening is controversial since it has been suggested that both colonoscopy and FIT are less effective for detecting lesions located in the proximal colon than in the distal colon. ${ }^{37}$ A casecontrol study showed that colonoscopy was strongly associated with a reduction in mortality from left-sided colorectal cancer but not from right-sided tumors. ${ }^{9}$ FIT seems to detect lesions that are mainly located distally to the splenic flexure. ${ }^{38}$ In this interim analysis, we observed no significant between-group difference in side-specific colorectal-cancer detection, but more advanced and nonadvanced adenomas in both the proximal and distal colon were detected in the colonoscopy group than in the FIT group. This difference was significantly higher for advanced adenomas in the proximal colon than in the distal colon. Precise explanations for these differential findings or how they may influence long-term results are unclear.

In summary, in this interim analysis, subjects in the FIT group were more likely to participate in colorectal-cancer screening than subjects in the colonoscopy group. On the baseline screening examination, the number of subjects in whom colorectal cancer was detected was similar in the two study groups, but more adenomas were detected in the colonoscopy group. The comparative effectiveness of FIT and colonoscopy for preventing death from colorectal cancer will be assessed at the completion of this 10-year trial.

Supported by grants from Asociación Española contra el Cáncer (Fundación Científica and Junta de Barcelona), Instituto de Salud Carlos III (PI08/90717), FEDER funds, and Agència de Gestió d'Ajuts Universitaris i de Recerca (2009SGR849). Centro de Investigación Biomédica en Red de Enfermedades Hepáticas y Digestivas (CIBERehd) is funded by Instituto de Salud Carlos III. In the Basque Country, the study received additional grants from Obra Social de Kutxa, Diputación Foral de Gipuzkoa (DFG 07/5), Departamento de Sanidad del Gobierno Vasco, EITB-Maratoia (BIO 07/ CA/19), and Acción Transversal contra el Cáncer del CIBERehd (2008). In Galicia, this work was supported by Dirección Xeral de Innovación e Xestión da Saúde Pública, Conselleria de Sanidade, and Xunta de Galicia. Eiken Chemical of Japan and its Spanish representatives, Palex Medical and Biogen Diagnóstica, donated supplies and automated analyzers used for FIT.

Disclosure forms provided by the authors are available with the full text of this article at NEJM.org. 
The authors' affiliations are as follows: the Department of Gastroenterology, Hospital Universitario de Canarias, Tenerife (E.Q., I.A.-A.); the Department of Gastroenterology, Hospital Clínic, Centro de Investigación Biomédica en Red de Enfermedades Hepáticas y Digestivas (CIBERehd), Institut d'Ivestigacions Biomediques August Pi i Sunyer (A.C.), the Department of Gastroenterology, Parc de Salut Mar, Institut Municipal d'Investigació Mèdica (IMIM), Pompeu Fabra University (M. Andreu, X.B., O.F.-A.), the Department of Epidemiology and Evaluation, Parc de Salut Mar, IMIM (C.H.), and Unitat d'Avaluació, Suport i Preventiva, Hospital Clínic (J.G., A.S.) — all in Barcelona; the Department of Gastroenterology, Donostia Hospital, CIBERehd, University of Basque Country (L.B.), the Department of Gastroenterology, Instituto Oncológico, Obra Social Kutxa (I.M.), and the Department of Gastroenterology, Policlinica Gipuzkoa, CIBERehd J.A.) - all in San Sebastián; the Department of Gastroenterology, Complexo Hospitalario Universitario de Ourense, Ourense (J.C., E.C.); the Colorectal Cancer Screening Program, Dirección General de Salud Pública, Conselleria de Sanitat (D.S., T.S., M. Andres, G.T.), and the Department of Gastroenterology, Hospital Universitario La Fe (M.P.) - both in Valencia; the Department of Gastroenterology, University of Zaragoza, IIS Aragón, CIBERehd, Zaragoza (A.L., M.-P.R., M.P.-T.); Unidad de Gestión Clínica de Digestivo, Hospital Universitario Virgen de la Arrixaca (F.C., A.O.), the Colorectal Cancer Prevention Program of the Región de Murcia, Servicio Murciano de Salud (J.C.), and the Colorectal Cancer Prevention Program of the Región de Murcia, Dirección General de Salud Pública, Consejería de Sanidad y Política Social (F.P.-R.) - all in Murcia; the Department of Gastroenterology, Hospital Clínico San Carlos (J.D.M., C.P.), the Department of Gastroenterology, Hospital Fundación Alcorcón (G.C.), the Department of Gastroenterology, Hospital 12 de Octubre (J.D.-T.), the Department of Gastroenterology, Hospital de la Princesa, Instituto de Investigación Sanitaria Princesa (IP), and CIBERehd (C.S.), and the Regional Office for Oncology Coordination, Consejería de Sanidad (A.G.-N.) — all in Madrid; the Gastroenterology Unit, Hospital General Universitario de Alicante, Alicante (R.J.); the Department of Gastroenterology, Lasarte-Oria Health Center, Osakidetza-Basque Health Service, Guipúzcoa (E.L.); the Department of Gastroenterology, Complexo Hospitalario Universitario de Vigo, Vigo (V.H., F.I.); Dirección Xeral de Innovación e Xestión da Saúde Pública, Conselleria de Sanidade, Xunta de Galicia (R.Z.); the Department of Gastroenterology, Consorcio Hospitalario de Castellón, Castellón (A.P.); the Colorectal Cancer Screening Program of the Comunidad de Canarias, Servicio Canario de la Salud (M.V.-P., J.M.R.-M.); and the Department of Gastroenterology, Hospital Puerta de Hierro, Majadahonda (A.H.-T.) — all in Spain.

REFERENCES

1. Ferlay J, Shin HR, Bray F, Forman D, Mathers C, Parkin DM. Estimates of worldwide burden of cancer in 2008: GLOBOCAN 2008. Int J Cancer 2010;127:2893-917.

2. Levin B, Lieberman DA, McFarland B, et al. Screening and surveillance for the early detection of colorectal cancer and adenomatous polyps, 2008: a joint guideline from the American Cancer Society, the US Multi-Society Task Force on Colorectal Cancer, and the American College of Radiology. Gastroenterology 2008;134:1570-95. 3. Mandel JS, Church TR, Bond JH, et al. The effect of fecal occult-blood screening on the incidence of colorectal cancer. N Engl J Med 2000;343:1603-7.

4. Hewitson P, Glasziou P, Watson E, Towler B, Irwig L. Cochrane systematic review of colorectal cancer screening using the fecal occult blood test (Hemoccult): an update. Am J Gastroenterol 2008; 103:1541-9.

5. Atkin WS, Edwards R, Kralj-Hans I, et al. Once-only flexible sigmoidoscopy screening in prevention of colorectal cancer: a multicentre randomised controlled trial. Lancet 2010;375:1624-33.

6. Heitman SJ, Hilsden RJ, Au F, Dowden S, Manns BJ. Colorectal cancer screening for average-risk North Americans: an economic evaluation. PLoS Med 2010;7(11): 1000370.

7. Brenner H, Chang-Claude J, Seiler CM, Rickert A, Hoffmeister M. Protection from colorectal cancer after colonoscopy: a population-based, case-control study. Ann Intern Med 2011;154:22-30.

8. Brenner H, Haug U, Arndt V, Stegmaier C, Altenhofen L, Hoffmeister M. Low risk of colorectal cancer and advanced ad- enomas more than 10 years after negative colonoscopy. Gastroenterology 2010;138: 870-6.

9. Baxter NN, Goldwasser MA, Paszat LF, Saskin R, Urbach DR, Rabeneck L. Association of colonoscopy and death from colorectal cancer. Ann Intern Med 2009; 150:1-8.

10. Brenner $\mathrm{H}$, Chang-Claude J, Seiler $\mathrm{CM}$, Hoffmeister M. Long-term risk of colorectal cancer after negative colonoscopy. J Clin Oncol 2011;29:3761-7.

11. Imperiale TF, Glowinski EA, LinCooper C, Larkin GN, Rogge JD, Ransohoff DF. Five-year risk of colorectal neoplasia after negative screening colonoscopy. N Engl J Med 2008;359:1218-24. [Erratum, N Engl J Med 2009;361:2004.]

12. Kahi CJ, Imperiale TF, Juliar BE, Rex DK. Effect of screening colonoscopy on colorectal cancer incidence and mortality. Clin Gastroenterol Hepatol 2009;7:770-5, quiz 711 .

13. Citarda F, Tomaselli G, Capocaccia R, Barcherini S, Crespi M. Efficacy in standard clinical practice of colonoscopic polypectomy in reducing colorectal cancer incidence. Gut 2001;48:812-5.

14. Winawer SJ, Zauber AG, Ho MN, et al. Prevention of colorectal cancer by colonoscopic polypectomy. N Engl J Med 1993; 329:1977-81.

15. Dancourt V, Lejeune C, Lepage C, Gailliard MC, Meny B, Faivre J. Immunochemical faecal occult blood tests are superior to guaiac-based tests for the detection of colorectal neoplasms. Eur J Cancer 2008;44:2254-8

16. Hol L, Wilschut JA, van Ballegooijen $\mathrm{M}$, et al. Screening for colorectal cancer: random comparison of guaiac and immunochemical faecal occult blood testing at different cut-off levels. Br J Cancer 2009; 100:1103-10.

17. Parra-Blanco A, Gimeno-García AZ, Quintero E, et al. Diagnostic accuracy of immunochemical versus guaiac faecal occult blood tests for colorectal cancer screening. J Gastroenterol 2010;45:703-12. 18. van Rossum LG, van Rijn AF, Laheij RJ, et al. Random comparison of guaiac and immunochemical fecal occult blood tests for colorectal cancer in a screening population. Gastroenterology 2008;135: 82-90.

19. Levi Z, Birkenfeld S, Vilkin A, et al. A higher detection rate for colorectal cancer and advanced adenomatous polyp for screening with immunochemical fecal occult blood test than guaiac fecal occult blood test, despite lower compliance rate: a prospective, controlled, feasibility study. Int J Cancer 2011;128:2415-24.

20. Hol L, van Leerdam ME, van Ballegooijen $M$, et al. Screening for colorectal cancer: randomised trial comparing guaiacbased and immunochemical faecal occult blood testing and flexible sigmoidoscopy. Gut 2010;59:62-8.

21. Segnan N, Senore C, Andreoni B, et al. Comparing attendance and detection rate of colonoscopy with sigmoidoscopy and FIT for colorectal cancer screening. Gastroenterology 2007;132:2304-12.

22. Andreu García M, Marzo M, Mascort $\mathrm{J}$, et al. Prevention of colorectal cancer. Gastroenterol Hepatol 2009;32:137-9. (In Spanish.)

23. Castells A, Castellví-Bel S, Balaguer F. Concepts in familial colorectal cancer: 
where do we stand and what is the future? Gastroenterology 2009;137:404-9.

24. Piñol V, Castells A, Andreu M, et al. Accuracy of revised Bethesda guidelines, microsatellite instability, and immunohistochemistry for the identification of patients with hereditary nonpolyposis colorectal cancer. JAMA 2005;293:1986-94. 25. Parra-Blanco A, Nicolas-Perez D, Gimeno-Garcia A, et al. The timing of bowel preparation before colonoscopy determines the quality of cleansing, and is a significant factor contributing to the detection of flat lesions: a randomized study. World J Gastroenterol 2006;12:6161-6.

26. Guía de práctica clínica de calidad en la colonoscopia de cribado del cáncer colorrectal. Asociación Española de Gastroenterología y Sociedad Española de Endoscopia Digestiva, 2011 (http://www.aegastro .es/docs/cribado_colon.pdf).

27. O'Connell JB, Maggard MA, Ko CY. Colon cancer survival rates with the new American Joint Committee on Cancer sixth edition staging. J Natl Cancer Inst 2004;96:1420-5.
28. Vilkin A, Rozen P, Levi Z, et al. Performance characteristics and evaluation of an automated-developed and quantitative, immunochemical, fecal occult blood screening test. Am J Gastroenterol 2005; 100:2519-25.

29. Scholefield JH, Moss SM. Faecal occult blood screening for colorectal cancer. J Med Screen 2002;9:54-5.

30. Hollis $\mathrm{S}$, Campbell $\mathrm{F}$. What is meant by intention to treat analysis? Survey of published randomised controlled trials. BMJ 1999;319:670-4.

31. Lieberman D. A call to action - measuring the quality of colonoscopy. N Engl J Med 2006;355:2588-9.

32. Arber N, Eagle CJ, Spicak J, et al. Celecoxib for the prevention of colorectal adenomatous polyps. N Engl J Med 2006; 355:885-95.

33. Baron JA, Cole BF, Sandler RS, et al. A randomized trial of aspirin to prevent colorectal adenomas. N Engl J Med 2003; 348:891-9.

34. Lieberman DA, Weiss DG, Bond JH, Ahnen DJ, Garewal H, Chejfec G. Use of colonoscopy to screen asymptomatic adults for colorectal cancer. N Engl J Med 2000; 343:162-8. [Erratum, N Engl J Med 2000; 343:1204.]

35. Lieberman DA, Weiss DG, Harford WV, et al. Five-year colon surveillance after screening colonoscopy. Gastroenterology 2007;133:1077-85.

36. European guidelines for quality assurance in colorectal cancer screening and diagnosis. Brussels: European Commission, 2011 (http://bookshop.europa.eu/ is-bin/INTERSHOP.enfinity/WFS/

EU-Bookshop-Site/en_GB/-/EUR/

ViewPublication-Start?PublicationKey= ND3210390).

37. Lieberman D. Colon cancer screening and surveillance controversies. Curr Opin Gastroenterol 2009;25:422-7.

38. Haug $U$, Kuntz KM, Knudsen $A B$, Hundt S, Brenner H. Sensitivity of immunochemical faecal occult blood testing for detecting left- vs right-sided colorectal neoplasia. Br J Cancer 2011;104:1779-85. Copyright (c) 2012 Massachusetts Medical Society.

The NEJM Image Challenge app brings a popular online feature to the smartphone. Optimized for viewing on the iPhone and iPod Touch, the Image Challenge app lets you test your diagnostic skills anytime, anywhere. The Image Challenge app randomly selects from 300 challenging clinical photos published in NEJM, with a new image added each week. View an image, choose your answer, get immediate feedback, and see how others answered.

The Image Challenge app is available at the iTunes App Store. 